\title{
The Nature of Zolon Red
}

A. M. Qureshi and A. N. Patel

Department of Chemistry, University of Nigeria, Nsukka, Nigeria

Z. Naturforsch. $33 \mathrm{~b}, 450-453$ (1978); received November 28, 1977

Pyrazolone Dye, Zolon Red

Zolon red is an acid dye obtained in the enol form as the stable condensation product of glutaconic aldehyde with two molecules of 1-phenyl-3-methylpyrazol-5-one. Silver(I) replaces the hydroxylhydrogen of the dye to give deep blue precipitate of silver-zolon red compound.

\section{Introduction}

Pyridine and pyrazolone reagents had long been used for the detection and estimation of micro amounts of cyanides and ammonia [1-3]. The procedure involves the production of a blue dye by the interaction of pyridine and pyrazolone in the presence of chloramine $\mathrm{T}$ and sodium cyanide. Initially glutaconic aldehyde is formed by the opening of pyridine ring of pyridinium cyanide chloride which reacts with two molecules of 1 . phenyl-3-methylpyrazol-5-one to give a blue dye which obeys the Beer-Lambert Law. The solution of the blue dye known as zolon blue was found to be unstable and could be converted to a red dye by boiling for short period in aqueous alkali [4]. The red dye to which the name zolon red was given forms coloured precipitates not only with silver(I), mercury(II) and copper(I) [4] but also with mercury(I) and palladium(II). Analytical application of zolon red as a gravimetric, spectrophotometric and extracting reagent for silver have been investigated [5-6]. The structure was assigned to zolon red [7] which represents the keto form of the condensation product of glutaconic aldehyde with two molecules of 1-phenyl-3-methylpyrazol-5-one. This work describes the nature of zolon red in detail and provides evidences in favour of enol form of the structure 4.

\section{Experimental}

\section{Preparation of zolon blue}

$9.0 \mathrm{~g}$ of 1-phenyl-3-methylpyrazol-5-one was mixed with $2.0 \mathrm{ml}$ pyridine to form a paste and then diluted with a solution of $1.25 \mathrm{~g}$ sodium cyanide in $125 \mathrm{ml}$ water. The suspension so produced was treated with $7.0 \mathrm{~g}$ chloramine $\mathrm{T}$ in $125 \mathrm{ml}$ water dropwise and with constant stirring. A red colour

Requests for reprints should be sent to Dr. A. M. Qureshi, Department of Chemistry, University of Nigeria, Nsukka, Nigeria.
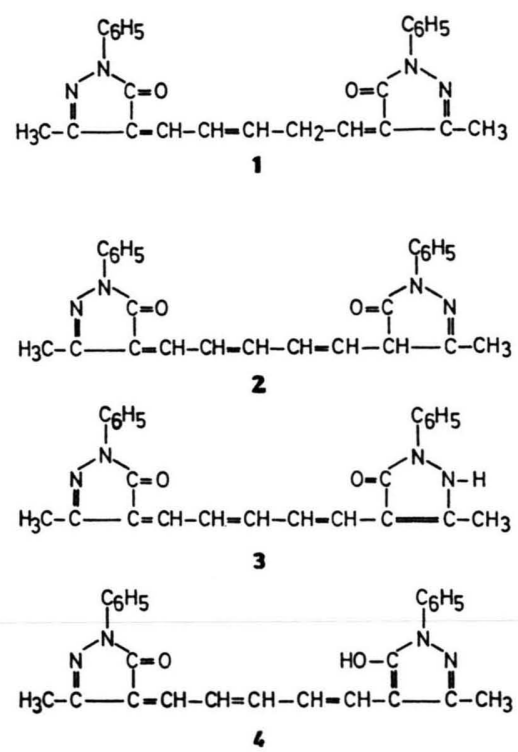

Fig. 1. Tautomeric forms of zolon blue-zolon red systems.

was produced which immediately turned to blue paste. The stirring was continued for 20-30 min until the test made by placing a drop of the reaction mixture on filter paper gave a blue spot. However, due to unstability of the blue dye a trace of red ring might be observed around the central blue spot. The blue dye so obtained smelled like pyridine and was soluble in water. It was recrystallised with acetone and dried over phosphorus pentoxide.

Analysis for $\mathrm{C}_{25} \mathrm{H}_{22} \mathrm{~N}_{4} \mathrm{O}_{2}$

Calcd C 73.17 H 5.37 N 13.65,

Found C 72.68 H 5.36 N 14.09.

\section{Preparation of zolon red}

First the blue dye was prepared, as described above, filtered and washed with $50 \mathrm{ml}$ water. The dye was transferred into a beaker and a paste was made with a minimum amount of water. Then a solution of $10 \mathrm{~g}$ anhydrous sodium carbonate in $125 \mathrm{ml}$ water was added and the mixture was boiled. The colour changed from blue to purple to red. The boiling was continued until a drop of the reaction 
mixture on filter paper gave a red orange spot. A thick red product was obtained on cooling which was filtered with suction and washed twice with $50 \mathrm{ml}$ water. The red compound was dissolved in $300 \mathrm{ml}$ water and reprecipitated by adding a slight excess of $10 \%$ hydrochloric acid. The red dye was filtered and washed well with water. It was recrystallised with methanol and acetone and dried over phosphorus pentoxide. Yield $2.50 \mathrm{~g} ;$ m.p. $212^{\circ} \mathrm{C}$ (decomposes to a black mass).

$\begin{array}{ccccc}\text { Analysis for } \mathrm{C}_{25} \mathrm{H}_{22} \mathrm{~N}_{4} \mathrm{O}_{2} & & \\ \text { Calcd } & \mathrm{C} 73.17 & \mathrm{H} & 5.37 & \mathrm{~N} \\ \text { Found } & \mathrm{C} 72.87 & \mathrm{H} 5.36 & \mathrm{~N} \text { 13.85. }\end{array}$

\section{Molecular weight}

Molecular weight of zolon red in methanol was determined on Hitachi Perkin-Elmer Model 115 Molecular Weight Apparatus. Benzil (molecular weight 210.23) was used for caliberation. Molecular weight found 820.20 , calculated for $\mathrm{C}_{25} \mathrm{H}_{22} \mathrm{~N}_{4} \mathrm{O}_{2}$ 410.0 .

\section{Stoichiometry of reaction of zolon red with silver(I)}

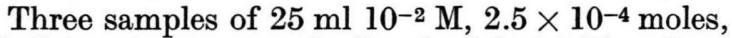
of silver nitrate were buffered with $0.1 \mathrm{M}$ sodium acetate and treated with $0.0513,0.1026$ and $0.2050 \mathrm{~g}$ of zolon red in minimum ethanol to give silver(I): zolon red ratio of $1: 0.5,1: 1$ and $1: 2$, respectively. The mixture was shaken, allowed to stand for $30 \mathrm{~min}$ in the dark and then filtered. The precipitates were washed well with water. Excess of silver(I) was determined in the filtrates and washings by cyanide method [8]. About half of the unreacted silver, $1.26 \times 10^{-4}$ moles, were present in the filtrate containing, silver $(\mathrm{I})$ : zolon red ratio $1: 0.5$. No silver was detected in the other two samples.

\section{Analysis of solid silver-zolon red compound}

$0.02336 \mathrm{~g}$ of solid silver-zolon red compound was dissolved in concentrated nitric acid and evaporated to dryness. The residue was treated with water, filtered and washed. Filtrate and washings were mixed with $25 \mathrm{ml} 0.104 \mathrm{M} \mathrm{KCN}$ and back titrated the excess of cyanide with $0.05 \mathrm{M}$ standard silver nitrate solution. It required $25.10 \mathrm{ml}$ of silver nitrate. Amount of silver in silver-zolon red compound was calculated. 20.67 .

Silver calculated for $\mathrm{AgC}_{25} \mathrm{H}_{21} \mathrm{~N}_{4} \mathrm{O}_{2} 20.87$, found

\section{Potentiometric titrations}

$25 \mathrm{ml}$ of $10^{-3} \mathrm{M}$ portions of zolon red in ethanol were titrated potentiometrically against $10^{-2} \mathrm{M}$ $\mathrm{NaOH}$ and $10^{-2} \mathrm{M} \mathrm{AgNO}_{3}$ solutions using $\mathrm{D}-812$ Weilheim direct reading $\mathrm{pH}$ meter.

\section{Spectroscopic studies}

1. NMR spectra were recorded on Varian T-60 NMR Spectrometer. Solutions were prepared in deuterated, $\mathrm{d}_{6}$-dimethylsulphoxide. TMS was used as standard. All chemical shifts are reported in $\delta$ values.

2. Infrared spectra of zolon blue, zolon red and silver-zolon red in Nujol mull were obtained with Perkin-Elmer 257 Infrared Spectrophotometer.

3. Electronic absorption spectra of zolon blue, zolon red and silver-zolon red in ethanol were taken on Unicam SP 500 Spectrophotometer.

\section{Discussion}

The blue and red dye have identical molecular formulas and the two isomers could be represented by the four most likely tautomeric forms as shown in Fig. 1.

Zolon Blue, even in vacuum and in the dark, slowly changes to red. The red dye, therefore, seems to be the most stable form of zolon blue-zolon red systems. The red dye decomposes to a black mass at its melting point $\left(212^{\circ} \mathrm{C}\right)$. It is sparingly soluble in water, chloroform and carbon tetrachloride but readily dissolves in alcohols, acetone, ether and dimethylsulphoxide. $98 \mathrm{mg}$ zolon red in $100 \mathrm{ml}$ ethanol give a saturated solution of orange colour. Zolon red forms a dimer in methanol and might be in other solvents perhaps through hydrogen bond which results in a molecular weight (820.20) twice that expected (410.0) for $\mathrm{C}_{25} \mathrm{H}_{22} \mathrm{~N}_{4} \mathrm{O}_{2}$.

Potentiometric titration of the red dye with sodium hydroxide has indicated zolon red, which would be referred as HZR, is a weak acid with a single dissociable hydrogen ion. It has a $\mathrm{pK}_{\mathrm{a}}$ value 3.80 as found by spectrophotometric determination. Silver(I) is not completely precipitated by HZR unless sodium acetate buffer is used. Stoichiometry of reaction of $\mathrm{HZR}$ with silver(I) buffered with sodium acetate indicated the formation of a deep blue, black when dry, 1:1 species which dissolves in alcohols and acids. The analysis of silver in the dried product has confirmed the stoichiometry of the reaction and formation of silver-zolon red in the ratio $1: 1$ [7].

The pH 3.90 of zolon red slowly dropped when $25 \mathrm{ml} 10^{-3} \mathrm{M}$ solution was titrated potentiometrically with $10^{-2} \mathrm{M}$ aqueous silver nitrate. The $\mathrm{pH}$ became constant ( $\mathrm{pH} 2.20$ ) after $2.70 \mathrm{ml}$ silver(I) had been added. This observation supports the view that zolon red is an acid which dissociates and forms insoluble compound with silver(I) according to the following reactions.

$$
\begin{aligned}
\mathrm{HZR} & \rightleftharpoons \mathrm{H}^{+}+\mathrm{ZR}^{-} \\
\mathrm{Ag}^{+}+\mathrm{ZR}^{-} & \rightleftharpoons \mathrm{AgZR}^{-}
\end{aligned}
$$


Further the solubility of silver-zolon red compound in acids and incomplete precipitation of silver(I) unless sodium acetate buffer is used suggests that the reaction between silver(I) and zolon red is reversible

$$
\mathrm{HZR}+\mathrm{Ag}^{+} \rightleftharpoons \mathrm{AgZR}+\mathrm{H}^{+}
$$

The dissociated hydrogen ions are removed in presence of acetate buffer and equilibrium of the above reaction is shifted towards right resulting complete precipitation of silver(I).

The presence of dissociable hydrogen is confirmed by the NMR spectra of zolon red which shows four types of proton resonances, one multiplet and three sharp singlets. The integral indicates that the multiplet between $\delta$ values of 7.00-8.00 corresponds to ten protons of the two phenyl groups in zolon red. The five-proton singlet at $\delta=4.40$ is assigned to the five protons of the system, ; $=\mathrm{CH}-\mathrm{CH}=\mathrm{CH}-\mathrm{CH}=\mathrm{CH}$-, and the six-proton singlet at $\delta=2.30$ is assigned to the six protons of the two methyl groups in the structure of zolon red. A sharp one-proton singlet at $\delta=2.06$ can be assigned to either the proton of the $: \mathrm{NH}$ group or to the proton of the $-\mathrm{OH}$ group in the structures 3 and 4, respectively. The presence of this signal in the NMR spectrum, therefore, eliminates the possibility of the structure $\mathbf{1}$ and $\mathbf{2}$ for zolon red. The singlet at $\delta=2.06$ disappears when the sample solution is shaken with a few drops of deuterium oxide and is absent in the NMR spectrum of zolon blue. This observation further supports the elimination of structure 1 and 2 and suggests forms 3 or 4 are possible structures for zolon red since the $=\mathrm{NH}$ proton and the $-\mathrm{OH}$ proton could equally be replaced by deuterium.

The absence of $=\mathrm{NH}$ group and the presence of $-\mathrm{OH}$ group in the structure of zolon red is confirmed by infrared spectrum. The peak frequencies of zolon blue, zolon red and silver-zolon red compound in the infrared spectra are recorded in Table I.

The blue dye does not show any absorption in the $-\mathrm{OH}$ and $=\mathrm{NH}$ stretching region if the spectrum is taken within two days of its preparation. However, after two days weak bands appear in the $-\mathrm{OH}$ and =NH regions and become more prominent after four days although the dye still looks blue. The blue dye completely changes to red after two weeks and the spectrum becomes identical with the spectrum of zolon red. The appearance of bands in the $-\mathrm{OH}$
Table I. Wave numbers $\left(\mathrm{cm}^{-1}\right)$ of peak frequencies.

\begin{tabular}{lcc}
\hline Zolon blue & Zolon red & Silver-zolon red \\
\hline 650 & 650 & 650 \\
665 & 660 & 665 \\
690 & 690 & 695 \\
752 & 758 & 752 \\
815 & 830 & 820 \\
992 & 1005 & 998 \\
1020 & 1030 & 1022 \\
1115 & 1120 & 1120 \\
1200 & 1195 & 1195 \\
1232 & 1240 & 1245 \\
1310 & 1335 & 1335 \\
$\overline{-}$ & 1495 & 1550 \\
1595 & 1560 & 1595 \\
- & 1595 & - \\
\hline
\end{tabular}

and $=\mathrm{NH}$ regions after two days in the blue dye is due to contamination with red dye because zolon blue is unstable and changes to zolon red which is the stable form of zolon blue-zolon red systems. Structures 1 and 2, therefore, may represent zolon blue but are ruled out for zolon red. The broad absorption at $3410 \mathrm{~cm}^{-1}$ and a strong at $1495 \mathrm{~cm}^{-1}$ in the infrared spectrum of red dye are assigned $-\mathrm{OH}$ stretching and $-\mathrm{OH}$ bending vibrations respectively. These vibrations disappear in silverzolon red compound which suggests that the hydroxyl-hydrogen is replaced by silver. The $=\mathrm{NH}$ stretching frequencies do occur in $3300-3500 \mathrm{~cm}^{-1}$ region and the imino-hydrogen could equally be replaced by silver but the $=\mathrm{NH}$ peaks are usually sharper. Further the absorption at $1560 \mathrm{~cm}^{-1}$ in zolon red and $1550 \mathrm{~cm}^{-1}$ in silver-zolon red compound which are assigned $>\mathrm{C}-\mathrm{O}$ stretching in $>\mathrm{C}-\mathrm{O}-\mathrm{H}$ group, are not in favour of structures 3 having =NH group. Structures 1, 2 and 3 represent only one type of carbonyl group, $=\mathrm{C}=\mathrm{O}$ whereas structure $\mathbf{4}$ is expected to show two types of $\mathrm{C}-\mathrm{O}$ stretching frequencies because of $=\mathrm{C}=\mathrm{O}$ and $>\mathrm{C}-\mathrm{O}-\mathrm{H}$ groups. Zolon red does exhibit a peak at $1560 \mathrm{~cm}^{-1}$ which is retained in silver-zolon red compound at $1550 \mathrm{~cm}^{-1}$. Infrared spectra, therefore, favours structure 4 for zolon red because of the presence of $-\mathrm{OH}$ group. The presence of $-\mathrm{OH}$ group rather $=\mathrm{NH}$ group in zolon red should not be surprising as most of the pyrazolone dyes e.g., Eriochrome red B and xylene yellow $3 \mathrm{G}$ contain $-\mathrm{OH}$ groups in their structures.

The wave lengths of maximum absorption of solutions of zolon blue, zolon red and silver-zolon red compound in ethanol in the ultraviolet and 
visible regions are recorded in Table II. Zolon red and silver-zolon red form orange and redpurple solutions respectively in organic solvents but both show maximum absorption at $255 \mathrm{~nm}$ and $520 \mathrm{~nm}$ in the electronic absorption spectra. The structure of silver-zolon red compound has not been investigated. However, it seems the silver compound is formed by ions association like silver acetate $\left(\mathrm{AgOOCH}_{3}\right)$ because complexes of silver(I) are not well known for oxygen ligands. The change of colour

Table II. The wave lengths (nm) of maximum absorption.

\begin{tabular}{lll}
\hline Compound & Colour of the solution & Max \\
\hline Zolon blue & Blue & $\mathbf{2 5 0 , 6 2 5}$ \\
Zolon red & Orange & $\mathbf{2 5 5 , 5 2 0}$ \\
Silver-zolon red & Redpurpule & $\mathbf{2 5 5 , 5 2 0}$ \\
\hline
\end{tabular}

of zolon red, when it reacts with silver(I), from orange to red-purple in solution and intense blue in solid is perhaps due to charge transfer transitions involving the ion pair, $\mathrm{Ag} \mathrm{ZR}^{-}$.

\section{Conclusion}

This work on the basis of chemical and spectroscopic studies supports the presence of hydroxyl group in the structure of zolon red and suggests it to be the enol form of the tautomers. Zolon red, therefore, should be best represented by structure 4.

We are thankful to Dr. S. A. H. Zaidi, Mr. F. I. Ozoh of the University of Nigeria and Dr. G. Webb of the University of Glasgow for their help in the determination of molecular weight and micro analysis. We would also like to thank Dr. J. U. Oguakwa and Dr. E. C. Okafor for useful discussions.
[1] Joseph Epstein, Anal. Chem. 19, 272 (1947).

[2] J. M. Kruse and M. G. Million, Anal. Chem. 25, 1188 (1953).

[3] Irith Gilath, Anal. Chem. 49, 516 (1977).

[4] B. Gehauf and J. Goldenson, Anal. Chem. 27, 420 (1955).

[5] A. M. Qureshi, D. A. Eba, A. I. Imo, and S. O. Aloke, unpublished work.
[6] A. N. Patel and A. M. Qureshi, Paper presented at ISEC'77, Toronto, Canada, September 1977.

[7] G. F. Svatos and J. Goldenson, J. Org. Chem. 21, 1171 (1956).

[8] A. I. Vogel, A Textbook of Quantitative Inorganic Analysis, p. 272, Longmans, London 1962. 